I Universidade Federal do Rio de Janeiro (UFRJ), Departamento

de Sociologia e Programa de Pós-Graduação em Sociologia e

Antropologia, Rio de Janeiro, RJ, Brasil

andrebotelho@digirotas.com.br

https://orcid.org/o0oo-000I-68I5-9040

André Botelho'

\title{
MINAS MUNDO: HERMENÊUTICA DE UMA SUBJETIVIDADE INDIVIDUAL*
}

Para Silviano

"Mínima moralia

A análise da sociedade pode valer-se muito mais da experiência do indivíduo do que Hegel faz crer. De maneira inversa, há margem para desconfiar que as grandes categorias da história podem enganar-nos, depois de tudo o que, neste meio tempo, foi feito em seu nome. Ao longo desses cento e cinquenta anos que passaram desde o aparecimento do pensamento hegeliano, é ao indivíduo que coube uma boa parte do potencial de protesto.

Theodor W. Adorno (1945)" Silviano Santiago, Em liberdade, I98I

Hoje em dia, seria difícil encontrar algum memorialista respeitável pronto a admitir um uso meramente instrumental do texto com vistas a consagrar a sua trajetória vivida fora do texto. Esse foi, entretanto, o sentido dominante na maior parte da precária história desse gênero literário no Brasil nos séculos XIX e XX, com raras e notáveis exceções. A prática autobiográfica parecia talhada para a consagração dos feitos dos seus autores que ou bem se consideravam proeminentes, ou bem sentiam necessidade de persuadir disso seus leitores (e si próprios, claro). Por certo, poder cultivar e acima de tudo transmitir suas lembranças e esquecimentos por meio da escrita é quase sempre recurso de distinção social e poder simbólico, sobretudo numa sociedade em que as práticas letradas costumam ser privilégio de classe.

Pedro Nava (I903-I984) talvez tenha se tornado o maior memorialista brasileiro, lugar ainda hoje incontrastável, mesmo tendo passado quase meio século da publicação do primeiro volume de suas memórias, a começar por ter inovado tanto nesse aspecto. Isto é, por ter investido tanto na composição da subjetividade individual dos seus narradores (embora uma narrativa em primeira pessoa, as Memórias têm dois narradores diferentes) e dos retratos que, 
experimentador das artes plásticas na juventude, Pedro Nava deixou de seus familiares, amigos, companheiros de geração. Nava parece ter preferido consagrar as Memórias como seu principal feito antes que a si próprio, por exemplo, como médico - embora também as tenha usado para criticar e se vingar de seus desafetos, sem esquecer o autoapreço pela linhagem familiar, que parece endêmico à prática memorialística entre nós.

As Memórias de Pedro Nava são compostas por Baú de ossos (I972), Balão cativo (I973), Chão de ferro (I976), Beira-mar (I978), Galo das trevas (I98I) e O círio perfeito (I983), além das 36 páginas de Cera das almas, o livro que daria continuidade à série interrompida pelo suicídio do autor, ocorrido em I3 de maio de 1984. Numa narrativa épica e passional marcada pelo excesso, já identificada ao barroco, que privilegia a percepção sensorial e em que o tratamento do detalhe busca capturar a atenção do leitor, as Memórias de Nava recriaram a sempre instável combinação de ficção e história, texto e contexto, em que o gênero se assenta. Além disso, mais do que nos temas exteriores, digamos, a contribuição de Pedro Nava ao gênero estará propriamente na figuração narrativa do complexo processo de interiorização do que lhe é exterior, a que podemos também chamar de socialização ou, ainda, de automodelagem da subjetividade individual a partir de uma escrita de si - uma prática reflexiva ao mesmo tempo de introspecção e de abertura para o outro, o leitor, mediante a qual o self se vai modelando.

Discrepando da prática histórica do memorialismo entre nós, Nava criou uma série de problemas formais duradouros para os especialistas, que têm frequentado suas memórias com assiduidade (Botelho, 20I2). E também problemas sociológicos. Afinal, sua narrativa simultaneamente reforça e contraria o horizonte de expectativas particular forjado entre autores e leitores, indicando processos sociais de longa duração no âmbito dos quais a individualização e as práticas de si que a acompanham parecem reiteradamente problemáticas. Entre nós, ainda hoje a categoria indivíduo não perdeu de todo o sentido pejorativo dado a ela historicamente no cotidiano, e a representação da família como unidade moral da sociedade vem se intensificando nos últimos anos com força impressionante, como se pode constatar em discursos religiosos, políticos e mesmo governamentais presentes na esfera pública.

Meu contato acadêmico com a obra memorialística de Pedro Nava levoume a uma série de perguntas que não têm recebido muita atenção na área do pensamento social brasileiro, minha área de pesquisa, e que apontam para as questões da subjetividade individual como relação social e do cosmopolitismo da/na cultura brasileira. Comento a seguir essa experiência particular como registro de pesquisas e experiências intelectuais em curso, um dos pontos de partida, aliás, para o projeto coletivo "Minas mundo: o cosmopolitismo na cul-

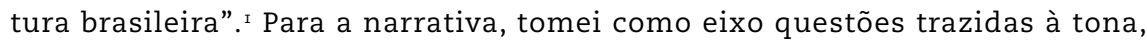
principalmente, em dois cursos ministrados na última década no Departamento de Sociologia da UFRJ relacionados à pesquisa em curso. 


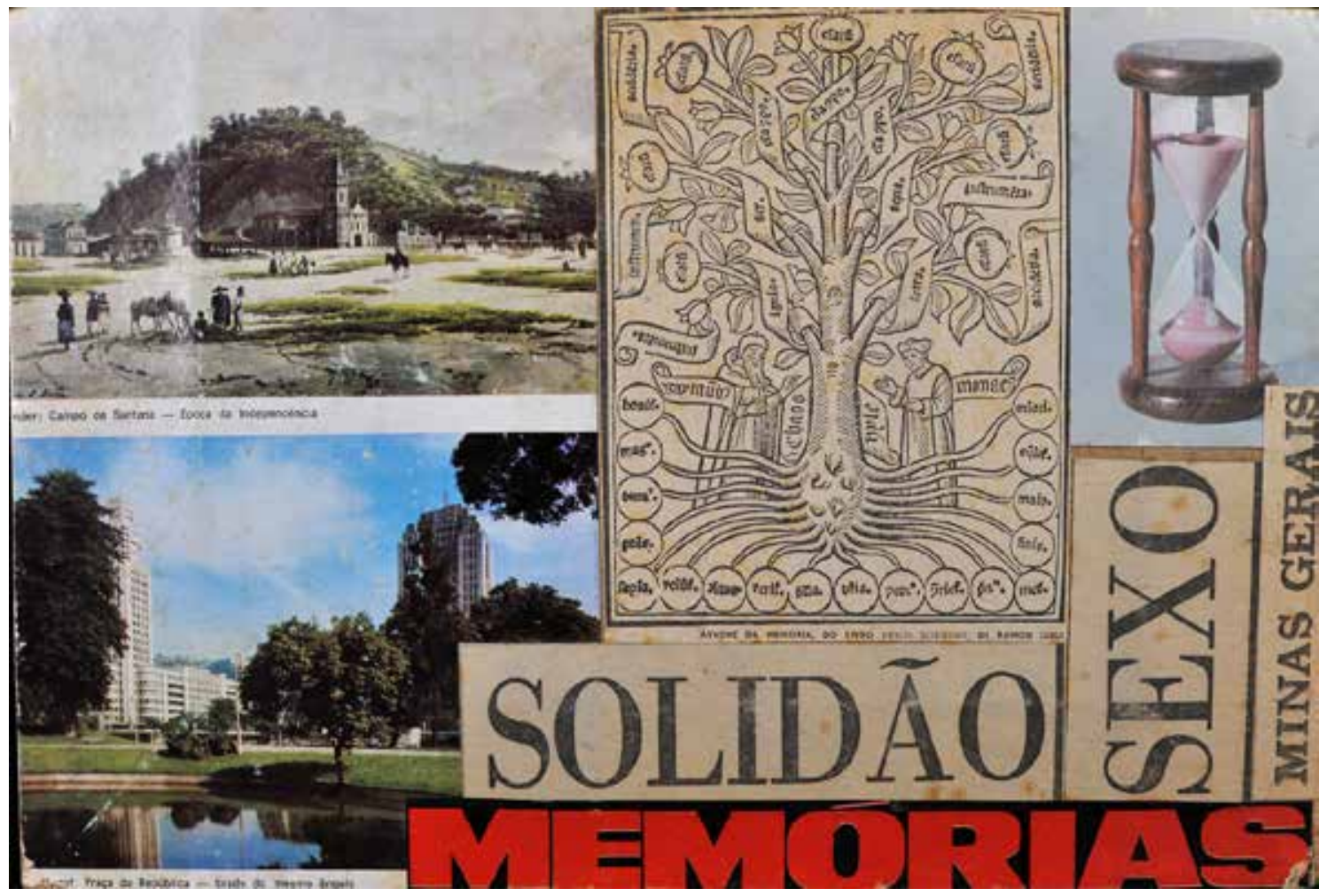

Pedro Nava, colagem, s.d. pasta Baú de ossos. Acervo Fundação Casa de Rui Barbosa/Arquivo Museu de Literatura Brasileira

Para essa reflexão sobre a figuração do indivíduo e de processos de subjetivação individual no memorialismo de Pedro Nava, lembro as sugestões de Silviano Santiago (I989: 3I), para quem "a narrativa autobiográfica é o elemento que catalisa uma série de questões teóricas gerais que só podem ser colocadas corretamente por intermédio dela". Como, aliás, ele mesmo vem explorando tanto na crítica quanto na ficção, como em seu romance Em liberdade, de I98I, de onde tomamos, como repetição, a epígrafe. Lembro ainda um ensaio crucial de Ricardo Benzaquen de Araújo (2004), "Através do espelho: subjetividade em Minha formação, de Joaquim Nabuco", a cuja apresentação oral, no Grupo de Pensamento Social no Brasil da Anpocs, eu tive o privilégio de assistir pessoalmente.

A relação entre indivíduo e sociedade é fundante da sociologia, como tão bem expressam os trabalhos de seus autores clássicos; afinal, o indivíduo e a sociologia são criações históricas contemporâneas da modernidade. Deles, Georg Simmel (20I I) foi um dos mais interessados numa perspectiva relacional 
(e não causal) do social que buscasse superar a dicotomia entre indivíduo e sociedade. A individualidade foi pensada, nesse sentido, como um fenômeno ligado às mudanças no padrão de relações sociais característico da modernidade. Atualmente, vemos emergir todo um campo identificado como sociologias do indivíduo por Danilo Martuccelli e François Singly (20 2), Las sociologías del individuo, ou Bernard Lahire (2002, 2004), O homem plural e Retratos sociológicos: disposições e variações individuais, por exemplo.

O interesse pelo indivíduo na disciplina tem-se mostrado potente o suficiente para atingir a própria teorização sociológica como um todo. Quando a individualização e a organização do eu como projeto reflexivo se impõem de maneira sem precedentes, torna-se necessário rediscutir a própria modernidade. Foi o que fizeram, entre outros, Ulrich Beck (20I I) em Sociedade de risco, Ulrich Beck e Elisabeth Beck-Gernsheim (2002) em Individualization: institutionalized individualism and its social and political consequences (2002) e Anthony Giddens (2002) em Modernidade e identidade, para citar apenas alguns de seus livros. O processo de individualização característico do que esses autores consideram a segunda modernidade ou modernidade reflexiva (historicamente, a partir do pós-Segunda Guerra Mundial) diz respeito, fundamentalmente, ao aumento das condições de possibilidade de uma espécie de imperativo moral a favor da autodeterminação pela escolha, segundo o qual, o indivíduo deve sempre pesar suas opções e fazer uma escolha, arcando com seus riscos.

Aqui o paradoxo social da individualização se recoloca: ao mesmo tempo em que o indivíduo é impulsionado a determinar e desenhar sua própria vida, encontra-se à mercê de uma série de constrições novas para o desenvolvimento de sua individualidade, a começar pelo próprio princípio de incerteza que a todos atinge. É para esse novo tipo de sociedade submetida a fortes e novos riscos ligados aos processos de individualização em curso que essa sociologia se volta: mudanças organizacionais do trabalho, dos estilos e modos de vida, das estruturas de poder e das formas de dominação política e de participação, da concepção de tempo, particularmente a compreensão sobre o futuro, alteram os laços sociais e parecem decretar o fim das biografias estáveis.

\section{CULTURA SUBJETIVA $X$ CULTURA OBJETIVA}

Se não me falha a memória... foi assim que começou. Há muito leitor dos romances e do memorialismo mineiros, em 2008 dei meu primeiro curso sobre Pedro Nava, uma disciplina optativa na graduação do IFCS/UFRJ. Na ocasião, me reuni a José Reginaldo Santos Gonçalves, referência incontornável nos temas da memória e patrimônio cultural, para juntos planejar e ministrar o curso. Chamamos a disciplina de Memória, narrativa e subjetividade. Na verdade, desde então não me desembaracei dessas questões.

Interessava-nos discutir o crescente interesse público pela memória e por diversas modalidades de representação do passado. Na forma de depoi- 
mentos testemunhais e autobiografias, de coleções, patrimônios, museus e comemorações ou ainda de documentários e filmes ficcionais, a memória se tornara presença constante nos meios de comunicação e uma espécie de obsessão coletiva.

Organizamos o curso para discutir comparativamente a categoria memória, focalizando os processos sociais e culturais de sua construção, detendo-nos em algumas formas específicas que ela pode assumir no contexto da modernidade. Um dos nossos propósitos era desnaturalizar as representações correntes de memória, que tendem a entendê-la como um dado psicológico, propriedade de um sujeito fixo e de um espírito humano permanente, infenso à história; ou, ainda, como uma invenção coletiva arbitrária, produzida de forma programática com o propósito de justificar ideologicamente as condições sociais e políticas. Reconhecemos assim não apenas a dimensão social e culturalmente construída da memória, mas também a natureza problemática, parcial e indeterminada das representações individuais e coletivas sobre o passado, simultaneamente fundadas nas experiências do presente e projetadas no futuro.

Dividimos o curso em três módulos. No primeiro, exploramos diferentes dimensões da categoria memória que permitiram, a partir daí, um tratamento socioantropológico consistente de uma de suas formas específicas: a escrita das memórias, gênero que faculta problematizar justamente as relações entre memória individual e coletiva, entre ficção e realidade, entre imaginação e documento. O gênero memórias foi o tema do segundo módulo, que combinou a leitura de textos teóricos gerais com interpretações circunstanciadas das Memórias de Pedro Nava para, em especial, especificar a formalização narrativa de circunstâncias de caráter social significativas como modos de existência. Baú de ossos (1972), primeiro volume das Memórias, foi, enfim, o objeto do terceiro módulo do curso.

As leituras teóricas envolveram autores como Jean-Pierre Vernant (Mito e pensamento entre os gregos), Frances Yates (A arte da memória), Maurice Halbawacs (A memória coletiva), Paul Ricoeur ("A inquietante estranheza da história”), Georg Simmel ("As grandes cidades e a vida do espírito"), Walter Benjamin ("Sobre alguns temas em Baudelaire" e "O narrador: considerações sobre a obra de Nicolai Leskov"), entre outros.

Sem dúvida foi nesse momento inicial que se definiu meu interesse pela questão do conflito entre indivíduo e sociedade no memorialismo de Pedro Nava, mais especificamente, para colocar em termos simmelianos, tão caros a José Reginaldo, que desde então me orientam teoricamente: sujeitos que estamos no fluxo da vida social ao jogo de forças contrapostas, o conflito entre indivíduo e sociedade é parte da cisão entre cultura objetiva e cultura subjetiva que dá forma à tragédia da cultura na modernidade - o grande tema da sociologia de Simmel. Na modernidade, o descompasso entre tudo aquilo que 
os indivíduos produzem fora de sua subjetividade, a cultura objetiva, e o cultivo pessoal, interior, da individualidade alcança um nível extremamente assimétrico, gerando uma separação radical entre o indivíduo e seu potencial criativo, por conta da própria intensificação da divisão social do trabalho. E essa cisão adquire sentido trágico justamente porque, em Simmel (20I I), a ação humana está sempre relacionada à ideia de criatividade originada da subjetividade.

\section{GENEALOGIA DE UMA SUBJETIVIDADE INDIVIDUAL}

No segundo semestre de 2019 voltei a ministrar disciplina sobre Pedro Nava. Dessa feita, diretamente para discutir construção da subjetividade e individualização na sociedade brasileira. Mais especificamente, possibilidades, limites e sentidos da construção do self em contexto histórico patriarcal a partir das relações entre indivíduo, família e sociedade na formação sentimental, moral e intelectual de dois narradores brasileiros: em Dom Casmurro (I 900), de Machado de Assis, e em Baú de ossos (I972). Discursos e atos dos discursos foram as categorias heurísticas exploradas, a partir das quais problematizei concepções mais tradicionais sobre gêneros literários, das quais, de certa maneira, eu mesmo partira anos atrás, já que, desse ponto de vista, a disciplina envolveria um romance, de um lado, e um livro de memórias, de outro. Em ambos os casos, porém, memória, ficção e autobiografia se entrelaçam em atos discursivos literária e esteticamente meditados e intencionados, que exigem, portanto, uma agenda renovada de pesquisa sobre questões de narratividade e verossimilhança, centrais também para uma nova sociologia da literatura (Botelho \& Hoelz, 20I6). Em outras palavras, quis discutir esse movimento de ressemantização do sujeito pelo próprio sujeito, ou seja, processos de subjetivação na cultura brasileira.

Do ponto de vista sociológico, a disciplina explorou as possibilidades de desnaturalização do indivíduo, isto é, de problematização da relação entre indivíduo e sociedade em debates recentes, como os já apontados. As leituras feitas na disciplina (e as preparatórias para ela) no campo da sociologia, da crítica literária e história das ideias foram igualmente decisivas para recolocar o memorialismo de Pedro Nava como parte de uma hermenêutica do sujeito. Isto é, para a investigação de uma genealogia do indivíduo e da moral burguesa, que, ademais, dá forma ao romance, em geral, e ao memorialismo, em particular, ao mesmo tempo em que é por eles alimentada extensa e intensivamente.

Importante de modo especial foi a leitura da transcrição das aulas do Curso no Collège de France de Michel Foucault $(2016,2006)$ reunidas sob os títulos Subjetividade e verdade, as de I980-I98I, e A hermenêutica do sujeito, as de I98I-I982, respectivamente. Essas aulas marcam um importante deslocamento nas preocupações básicas de Foucault. Suas pesquisas anteriores, pratica- 
mente restritas ao binômio saber e poder, são reorientadas para uma terceira dimensão, ou seja, pelo que ficou sendo conhecido como modos de subjetivação, colocando de maneira explícita a seguinte questão: de que maneira o sujeito foi estabelecido como objeto do conhecimento possível, desejável ou até mesmo indispensável, em diferentes momentos históricos e contextos institucionais. As técnicas de si são justamente os procedimentos pressupostos ou prescritos aos indivíduos para fixar sua identidade, mantê-la ou transformá-la, graças a relações de domínio de si sobre si ou de conhecimento de si por si.

Nessa direção, "Cadê Zazá? Ou a vida como obra de arte", de Silviano Santiago (2008), ensaio recolhido no livro O cosmopolitismo do pobre, foi crucial para a discussão da hermenêutica do sujeito e das relações do governo de si por si com o outro e com a comunidade, bem como para a discussão de como a arte de si mesmo se alicerça em fundamentos éticos. O texto de Silviano compreende além disso um verdadeiro roteiro para o enfrentamento dessas questões, com indicações bibliográficas extremamente generosas. Também os ensaios de Philippe Lejeune (2000) reunidos em O pacto autobiográfico e o livro de Wander Melo Miranda (2009), Corpos escritos: memória e autobiografia foram fundamentais - especialmente a ideia de indivíduo pressuposta pelo texto como critério de diferenciação das escritas de si. Ainda outra leitura marcante foi a do texto de Nancy Armstrong (2009), recolhido em A cultura do romance, organizado por Franco Moretti.

O argumento de Armstrong mostrou-se extremamente produtivo para a reflexão sobre um caso, talvez, fora da curva na história do individualismo ocidental e, portanto, do romance, como o Brasil. Afirma a autora que a moral burguesa é "a nossa forma específica de pensamento mágico, e o romance seu modo de difusão mais eficaz" (Armstrong, 2009: 336) - pois, como não negligencia, a moral burguesa atribui a esse indivíduo algo que não é individual: a possibilidade de conquistar uma posição social gratificante. Afinal, se no caso do romance europeu, o modelo em que um protagonista se opõe à ordem social estabelecida chega a um equilíbrio quando esse protagonista conquista uma posição compatível com seu valor, no caso brasileiro o campo inteiro das possíveis identidades não se modifica substantivamente para lhe garantir essa posição.

Sem me deter no problema, assinalo sua relação com a estrutura social brasileira e suas formas típicas de mobilidade individual, especialmente dos grupos intermediários ou classes médias, já que são fundamentais para pensar uma cultura do romance (Watt, 2010) e também do memorialismo brasileiro. Antonio Brasil Jr. e eu estudamos o problema na obra de Florestan Fernandes e constatamos a atualidade de seu diagnóstico em pesquisas recente (Brasil Jr. \& Botelho, 2017). Florestan se mostrou sempre atento às camadas intermediárias no Brasil, sobretudo no que se refere aos limites estreitos de seu radicalismo político e a sua lealdade histórica aos interesses das camadas sociais do- 
minantes e sua ordem de privilégios em vez de sua associação com demandas democráticas mais gerais ou universalistas. Como argumentamos, Florestan mostra o quanto o processo de mobilidade social ascendente e de permanente circulação de indivíduos de origem plebeia - ainda que só em escala individualizada, e não coletiva - nos espaços das camadas dirigentes está longe de ser um fenômeno apenas democratizante, pois a porosidade das hierarquias sociais revela-se compatível tanto com níveis extremos de desigualdades quanto com a reiteração de formas de socialização autocráticas avessas a uma filosofia democrática de vida, à legitimidade do conflito e à abertura universal do princípio da competição.

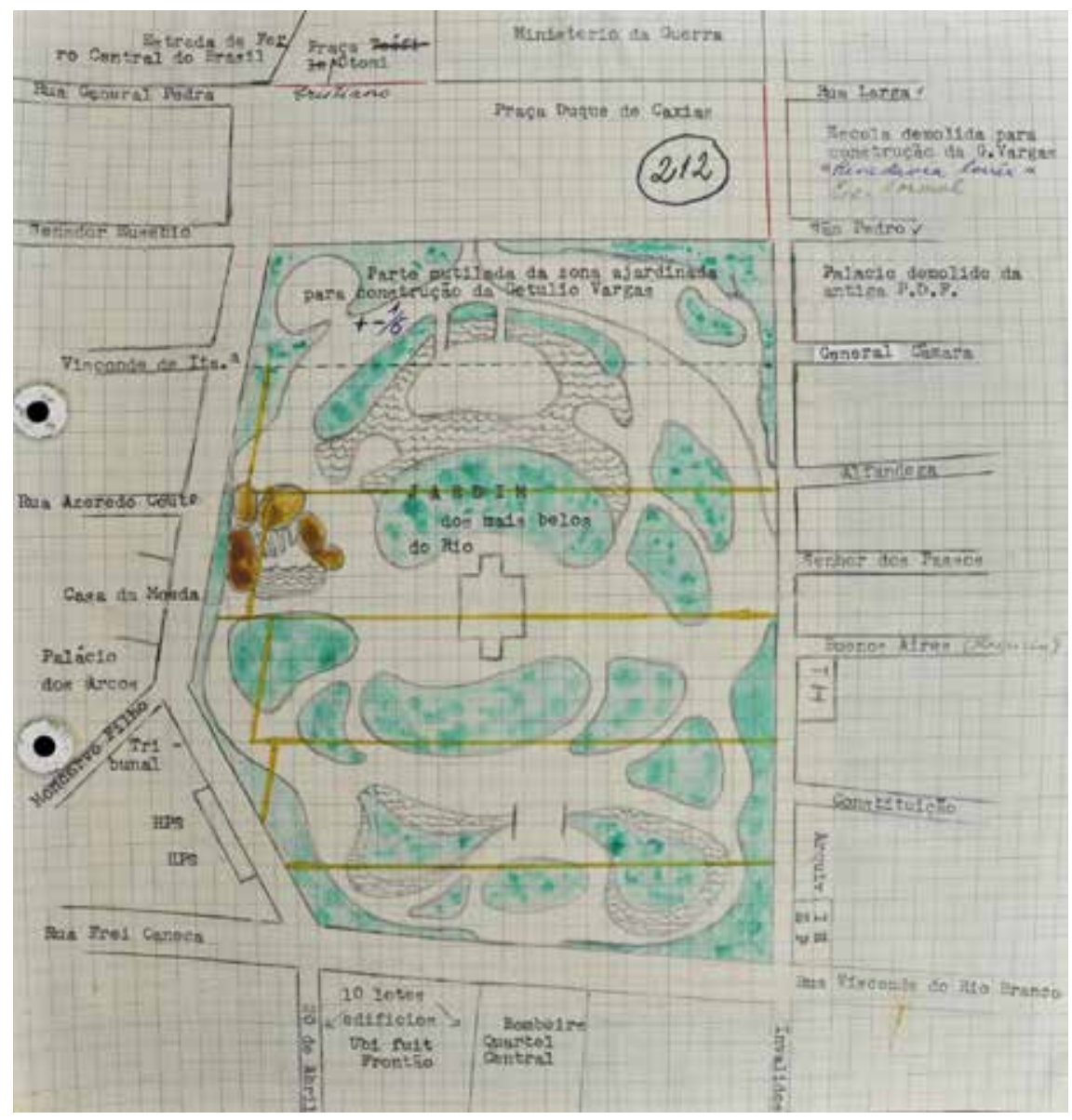

Pedro Nava, desenho, s.d. Mapa do entorno da praça da República (Campo de Santana), Centro do Rio de Janeiro. Pasta O círio perfeito. Acervo Fundação Casa de Rui Barbosa/Arquivo Museu de Literatura Brasileira 


\section{O COSMOPOLITISMO MINEIRO}

Justamente por isso, no meu último texto escrito sobre Pedro Nava argumentei que, tal como recriado em Beira-mar, o quarto volume das Memórias, dedicado ao período da juventude do narrador em Belo Horizonte, o modernismo mineiro parece constituir fundamentalmente um ímpeto contestador, tanto na estética quanto no comportamento da juventude, seus portadores sociais por excelência (Botelho, 20I9). Ímpeto contestador voltado especialmente contra a sociabilidade local da tradicional família mineira, tomada como fundamento moral e social, senão estético, do status quo. Atualizando em Beira-mar processos mais amplos de contraposição que estruturam a narrativa das Memórias em geral, como a oposição nos primeiros volumes entre a família paterna e a materna (polos positivo e negativo, respectivamente), a oposição entre juventude/ modernismo versus tradição/tradicional família mineira merece ser radicalizada para que se possa chegar o mais próximo possível da posição sempre parcial do narrador e do sentido sociológico próprio que encerra. Desse modo, Beira-mar parece contar, em grande medida, a história de moços bem-nascidos, mesmo que empobrecidos, que chocam a tradicional família mineira em Belo Horizonte, de que são membros legítimos e a partir de cujo horizonte, belo, com perdão do trocadilho, eles se colocam no mundo social que se desenha a sua frente. Aos menos favorecidos do mesmo estamento, era possível recorrer ao emprego público, de modo transitório ou não - como, em verdade, parece ser o caso de quase todos os rapazes do círculo do narrador, ainda que em diferentes patamares, como sugere o caso dos abastados irmãos Mello Franco. Uma nota sobre a Belo Horizonte do livro: a cidade planejada é moderna, mas parece, entretanto, se negar à impessoalidade da metrópole, posto que não apenas o espaço social é recriado a partir das famílias residentes vindas do interior (mesmo as de primeira geração), como também as experiências transgressoras que compreende (como "descer a Rua Bahia") parecem constituir contraponto necessário à própria reprodução de uma lógica familiar dominante.

O paradoxo do individualismo (Armstrong) que se expressa e alimenta o romance europeu e outras narrativas do eu explicita-se, assim, quase didaticamente. Para ser membros respeitáveis da sociedade, os indivíduos (protagonistas de romances europeus) devem se adaptar e observar as regras respeitadas pelos concidadãos; para concretizar algumas aspirações individuais, porém, precisam encontrar o modo de se expressar, o que só é possível forçando as regras que lhes definem a posição dentro da sociedade. O romance assume o dever de resolver essa contradição, criando situações imaginárias em que o protagonista pode se tornar um bom membro da sociedade, justamente ao se arriscar à exclusão.

Como no caso brasileiro, o círculo social raramente se amplia, de modo a tornar-se mais flexível e heterogêneo, para acolher os excluídos, a sociedade pouco se diversifica, pois não incorpora e atenua os excessos dos individualis- 
mos. Isso, porém, quase nunca é um problema no romance brasileiro. Nele há pouco espaço para as subjetividades individuais. Em contraste possível, no caso mineiro a saída para o protagonista tende a ser sua adaptação às normas culturais sufocando seus impulsos antissociais, pois a subjetividade individual existe. Daí que se possa tornar ao mesmo tempo mais profundo e complexo, frequentemente cada vez mais atormentado por conflitos internos como em alguns momentos (quase ritualmente) os narradores de Pedro Nava e, em casoslimite, até enlouqueça, como em Crônica da casa assassinada (I959), de Lúcio Cardoso.

Volto ao meu relato. Entre uma disciplina e outra na graduação do IFCS, na verdade, pude desenvolver e testar essa tópica em relação a Pedro Nava em experiências variadas: nas discussões com o grupo Memorialismo na América Latina, coordenado por Sergio Miceli e Carlos Altamirano (posteriormente por Jorge Meyers pelo lado argentino), em reuniões no Brasil e na Argentina - o livro com o resultado dessa pesquisa, Retratos latino-americanos, foi publicado em 20I9. Com a oportunidade que tive, graças aos editores e amigos Lili e Luiz Schwarcz, de coordenar e organizar, para a Companhia das Letras, a reedição das memórias de Pedro Nava (e prefaciar cada volume) iniciada em 2012. Por fim, Andre Bittencourt que trabalhou comigo na pesquisa para a reedição das Memórias na Casa de Rui Barbosa, onde se encontra o acervo do autor mineiro, posteriormente acabou escrevendo sua tese de doutorado, sob minha orientação, a respeito das ideias modernistas de chamado e de vocação em Pedro Nava e suas convergências e seus conflitos com a medicina praticada profissionalmente pelo memorialista mineiro (Bittencourt, 20I7). Sobre a edição das Memórias, trabalhamos primeiro no estabelecimento de texto - ideia posteriormente abandonada -, depois na seleção e composição dos cadernos de imagens dos volumes a partir do abundante material datiloscrito e iconográfico correspondente a cada um dos livros acondicionado pelo próprio Nava em pastas de cartolina coloridas em tons pastéis, típicas dos anos I980, que, aliás, inspiraram as capas soltas da edição.

Essas experiências, além das publicações propriamente acadêmicas que ensejaram, me colocaram diante de um problema delicado - em vários sentidos - sobre o conflito tênue, mas decisivo (os laços mais finos são os mais firmes, para evocar novamente Simmel) entre indivíduo e sociedade: uma subjetividade em busca dramática, não raro trágica, de individualização em meio à cultura objetiva representada pela família (a chamada tradicional família mineira) e pela sociedade e o Estado, inclementes estruturas de poder. Percepção despertada inicialmente por Pedro Nava e logo acentuada não apenas pelo memorialismo, mas também pelos romances e poemas de outros escritores mineiros, como Carlos Drummond, Cyro dos Anjos, Afonso Arinos, Lúcio Cardoso, Murilo Mendes, Otto Lara Resende etc. 


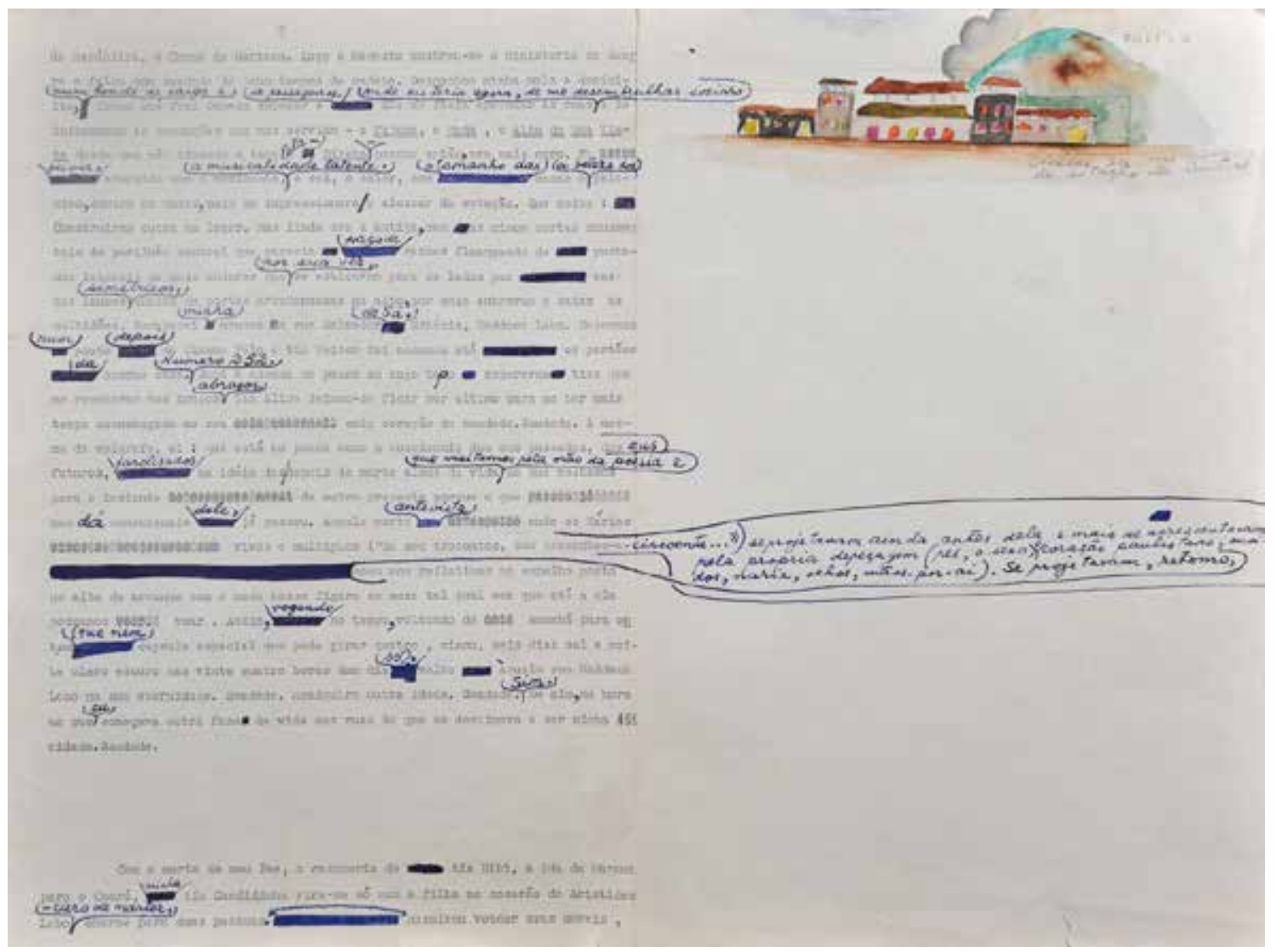

Pedro Nava, datiloscrito com desenho, s.d. Pasta Balão cativo. Acervo Fundação Casa de Rui Barbosa/Arquivo Museu de Literatura Brasileira

Uma experiência estranha que me parece ainda hoje contrastar com a tendência mais característica na cultura brasileira, como, por exemplo, o chamado romance social nordestino dos anos I930, em que se encena talvez não propriamente o conflito, mas a própria derrota ou mesmo supressão de uma subjetividade individual (das personagens de ficção, no caso. Lembremos a observação de Antonio Candido (2006a) sobre a força e a fraqueza dessa literatura, na qual o problema prepondera sobre a personagem). No caso mineiro, os indivíduos podem até ser derrotados pela família, pela sociedade ou pelo Estado, e frequentemente o são mesmo. Mas o conflito parece ser nele mais do 
que um tema; é o motivo principal da narrativa, o que o põe em movimento. Daí o cuidado com a caracterização tanto dos diferentes lados da contenda, beligerantes, o indivíduo, de um lado, a sociedade, de outro; quanto das próprias interações entre eles. Cultura subjetiva e cultura objetiva, distintas e em certo sentido irredutíveis uma à outra, mas em cuja interação cotidiana a vida social ganha forma, para lembrar Simmel novamente.

Resta uma questão importante (entre talvez muitas outras). Por que seria possível destacar e distinguir um caso mineiro de um brasileiro? Devo argumentar que a questão é parte dos problemas que, mais uma vez, apenas a pesquisa coletiva em curso poderá chegar a responder, se for esse o caso. Há, contudo, algumas pistas que eu mesmo encontrei pelo meu caminho. Compartilho-as a seguir. Não sem antes, porém, retomar minha advertência de que, ao destacar um caso mineiro, não tenho em vista buscar essencializar uma experiência histórica e social, mas antes questionar a ideia de homogeneidade da formação da sociedade brasileira. O que quer que seja mineiro é igualmente parte do problema a ser investigado e eventualmente explicado. Desenvolvimentos e problematizações da chamada mineiridade foram realizados, no âmbito da sociologia, por Maria Arminda do Nascimento Arruda (I989) e Helena Bomeny (I994), cujos livros são marcos importantes no debate.

\section{E POR QUE MINAS?}

A figuração do indivíduo e de processos de subjetivação no memorialismo de Pedro Nava, e que nos parece presente também no memorialismo e nos romance mineiros em geral, conjunto ainda por ser investigado empiricamente, contudo, aponta, a meu ver, para um traço cosmopolita marcante na formação social de Minas Gerais. Lembremos com Antonio Candido (2006b) que a urbanização precoce de Minas Gerais, comparativamente ao restante do Brasil e mesmo do continente, está na raiz do surgimento, no século XVIII, de uma literatura, em primeiro lugar, com um acentuado cunho de universalidade, como discutiu em "Poesia e ficção na autobiografia", famosa palestra de I976, posteriormente publicada em A educação pela noite. E, o que nos toca ainda mais diretamente, em segundo lugar, um gosto particular dos mineiros por literatura em primeira pessoa, em particular a autobiografia, assunto de seu texto que estamos evocando. No argumento de Candido, esses dois elementos se juntam, ademais, no tipo de tratamento característico dado pelos autores mineiros (ele está discutindo, sobretudo, Carlos Drummond de Andrade, Pedro Nava e Murilo Mendes) à própria autobiografia, isto é, na tendência que apresentam em extrair universalidade da matéria particular narrada, "a partir de algo tão contingente e particular como é em princípio a vida de cada um" (Candido, 2006b: 6I).

Como lembra Candido, as manifestações literárias do arcadismo constituíram um ponto de partida decisivo para toda a cultura de todo o Brasil, posto que as características tanto do barroco quanto do neoclassicismo estabeleceram 
uma "opção universalizante" traduzindo a "linguagem civilizada" do Ocidente em "terra semibárbara", como seria quase todo o Brasil daquela época (Candido, 2006b: 62). Em que pesem os termos enfáticos e o sentido eurocêntrico das afirmações, do ângulo que nos interessa, no momento, vale destacar antes dois pontos nessa argumentação sobre um perfil universalista da literatura produzida em Minas. Primeiro, o quanto deveríamos justamente a ela o polo universal da dialética entre particular/universal (local/cosmopolita) que organiza o pensamento de Candido, a oscilação entre os polos configurando uma espécie de dinâmica própria da cultura brasileira como cultura dependente (ver não apenas Formação da literatura brasileira, mas ainda "Cultura e subdesenvolvimento", entre outros de seus textos). Dialética que vigeria até os nossos dias e que se formara a partir do romantismo, a quem coube o papel de uma reação particularista e particularizante identificada ao nacionalismo, com seu "mergulho profundo nas particularidades do pitoresco e da cor local” (Candido, 2006b: 62).

$\mathrm{Se}$, como observa Candido, do romantismo aos nossos dias, aquele impulso inicial estaria fadado a ser encarado como um desvio do espírito nacional, como atraso no processo de autoidentificação da sociedade e da cultura nos termos de uma identidade brasileira, cabe-nos perguntar o quanto a formalização de um movimento de oscilação entre o particular e o universal em sua dialética não terá, talvez, domesticado demais a presença do cosmopolitismo na cultura brasileira. Afinal, o cosmopolitismo parece nela existir apenas para contrabalançar de modo funcional o impulso localista. Assinalada, deixo o desenvolvimento da questão para outra oportunidade. Seja como for, vamos reter nesse momento que é à civilização urbana de Minas que deveríamos aquele traço da nossa cultura e o eixo universalizante da dialética que, no século XIX, o século decisivo para a formação da literatura brasileira, assume a sua maturidade com Machado de Assis. Com Machado, afinal, observa Candido, "foi possível ver que o local e o universal, o transitório e o permanente, o particular e o geral estavam devidamente tecidos na sua carne, como na de qualquer literatura que vale alguma coisa" (Candido, 2006b: 62).

Recapitulando, o que nos interessa de mais perto por agora na discussão de Antonio Candido é, em primeiro lugar, sua hipótese de que a urbanização precoce de Minas Gerais não apenas teria dado lugar a uma opção universalizante em sua literatura desde o início e como isso ajuda a entender o porquê do florescimento da autobiografia em Minas e sua sofisticação a ponto de, na segunda metade do século XX, alguns de seus principais escritores problematizarem e mesmo redefinirem, entre nós, os princípios e as práticas tradicionais da autobiografia como gênero, confundindo memória, realidade e imaginação, amparados em recursos expressivos até então próprios da ficção. Em segundo lugar, o fato de esse gosto dos mineiros pela literatura em primeira pessoa ter-se traduzido de modo preponderante numa tendência de universalização do particular, a vida de cada um para uma vida de um "nós". 
Anos depois essa tendência apontada por Candido foi de certa forma retomada e expandida numa chave comparativa, muito importante para o argumento que estou desenvolvendo aqui. Refiro-me à comparação feita por Davi Arrigucci Jr. (200I), em "Móbile da memória”, entre Nava e Gilberto Freyre. Mostra o crítico como os sentidos do movimento de relacionar a memória pessoal e a sociedade são opostos nos dois autores: Freyre parte de vasta documentação que compõe o material da sua pesquisa sociológica para chegar a seu mundo de origem pessoal; Nava, ao contrário, parte da autobiografia para desenhar um retrato mais geral. Para Arrigucci Jr. (200I: I Io), embora a narrativa das Memórias, como também Casa-grande e senzala (I933), costeie perigosamente o tempo todo o discurso ideológico, a reconstrução do passado de uma classe social, isso não impediu que cada um deles chegasse, e cada qual a seu modo, a um conhecimento "geral dos modos de vida e sensibilidade da sociedade brasileira no seu dia a dia do passado, através de formas particulares e concretas de seu cotidiano, de repente chamadas à vida pelo toque de arte que aí desencadeou a ressurreição da memória". Mas o ponto, para nós, aqui, é o reforço do sentido de amplificação do individual - diríamos biografemas (com Roland Barthes) - na narrativa de Pedro Nava. Na narrativa mineira de Pedro Nava, poderíamos completar com Antonio Candido.

A comparação de Arrigucci Jr. fica por aqui. Nós é que, dando um passo atrás, na verdade, estamos nos perguntando sobre essa subjetividade individual tão contrastante entre os dois autores e, mais, entre as duas formações sociais a que estão ligados e que, de alguma forma, constroem em seus livros, a pernambucana, no caso de Freyre, e a mineira, no de Nava. Não parece significativo que a subjetividade individual trabalhe, em Freyre, justamente para recompor um perfil social do grupo, a família patriarcal? Afinal, o argumento decisivo de Casa-grande é justamente que a família patriarcal e não o indivíduo constitui a unidade da formação da sociedade brasileira. É ela a protagonista do ensaio de Freyre, na verdade, parte de uma reflexão mais ampla sobre o seu papel na construção da ordem numa sociedade tão violenta e polarizada (entre senhores e escravos) como a colonial (Bastos, 2006).

O contraste com a narrativa de Nava, a esse respeito, torna-se ainda mais forte se formos para o livro seguinte de Freyre, Sobrados e mucambos (I936), justamente dedicado à decadência da família patriarcal e à reorientação da vida social no sentido de sua urbanização/modernização/ocidentalização. Processo que também se fez acompanhar, no plano político, pelo progressivo declínio do poder privado, representado pelo patriarca, em face do também progressivo "aumento do poder político público, encarnado por órgãos judiciais, policiais, ou militares ou simplesmente burocráticos do governo monárquico" (Freyre, I98I: LXXI). Todavia, como a decadência do patriarcado rural não implicou totalmente o desaparecimento de seu poder, também a interpenetração entre público e privado não é rompida, ainda que as relações entre esses do- 
mínios se tenham alterado em decorrência do peso relativo que as instituições teriam passado a assumir - como expressa o fato de a ascensão social do bacharel e do mulato, bem como sua inserção no próprio domínio público, estar condicionada a suas relações tradicionais com a família patriarcal (Freyre, I 98I: 574-575).

A decadência da família patriarcal como princípio de organização da sociedade não dá lugar assim, no Brasil pernambucano de Gilberto Freyre, à emergência do indivíduo como entidade, nem diríamos autônoma, mas diferenciada subjetivamente da família a ponto de, como estamos argumentado para o caso das Memórias de Pedro Nava, o conflito entre indivíduo e sociedade poder ganhar figuração como princípio formal narrativo e social. Indivíduo e subjetividade individual permanecem, na nova ordem social e narrativa de Freyre, como que domesticados pela família patriarcal decadente.

o que a comparação me sugere, portanto, é que, primeiro, o lugar do indivíduo constitui uma clivagem importante para pensar diferentes figurações brasileiras do memorialismo e das narrativas em primeira pessoa em geral. E que, talvez, uma genealogia da subjetividade individual, como a que estamos propondo, possa ajudar a, direta e indiretamente, desentranhar o conflito sobre diferentes interpretações do Brasil desses textos-práticas de si, porque aquela clivagem também diz respeito às alternativas de país e às visões de sociedade ideal em disputa não apenas econômica, mas cultural e politicamente.

Lembro de passagem do instigante ensaio de Roberto Schwarz sobre a mineira Minha vida de menina, de Helena Morley. Em "Outra Capitu", de I997, o crítico se pergunta justamente como a decadência da mineração na região de Diamantina teria permitido uma prosa desataviada, irônica e crítica dos valores familiares, religiosos e sociais tradicionais assentados:

"Combinada à Abolição, sem a qual o resto não seria possível, a outra causa de progresso terá sido a decadência econômica da região. O paradoxo é interessante, pois ensina a ver a estreiteza dos progressismos correntes, desprovidos de antena para a melhora da sociedade. $\mathrm{O}$ avanço social eventualmente propiciado pelo declínio da economia é uma configuração que faz pensar. As melhoras que brotam no espaço aberto pela desativação dos negócios dominantes - ligados à acumulação capitalista mundial - são a crítica viva destes e da ordem que consolidam" (Schwarz, I991: 73-74).

A decadência econômica de Minas Gerais, devido ao esgotamento do ouro e dos diamantes, como bem observa Schwarz é questão das mais controversas entre especialistas. Aparece ora como uma involução, ora como crescimento peculiar. Num caso, a perda da relação com o mercado mundial de metais e pedras preciosas é vista como isolamento da região que leva quase a uma regressão da sociedade; em outro, o foco recai sobre os rearranjos muito particulares dessa mesma sociedade, que passa a se voltar para dentro, para os mercados locais e regionais. De modo que, realmente, podemos fazer nossas 
MINAS MUNDO: HERMENÊUTICA DE UMA SUBJETIVIDADE INDIVIDUAL

as palavras do crítico sobre o assunto: "O que é retrocesso para uns é avanço e civilização para outros, sendo que a opinião a respeito não pode ser igual nos diferentes setores da sociedade" (Schwarz, I991: 75).

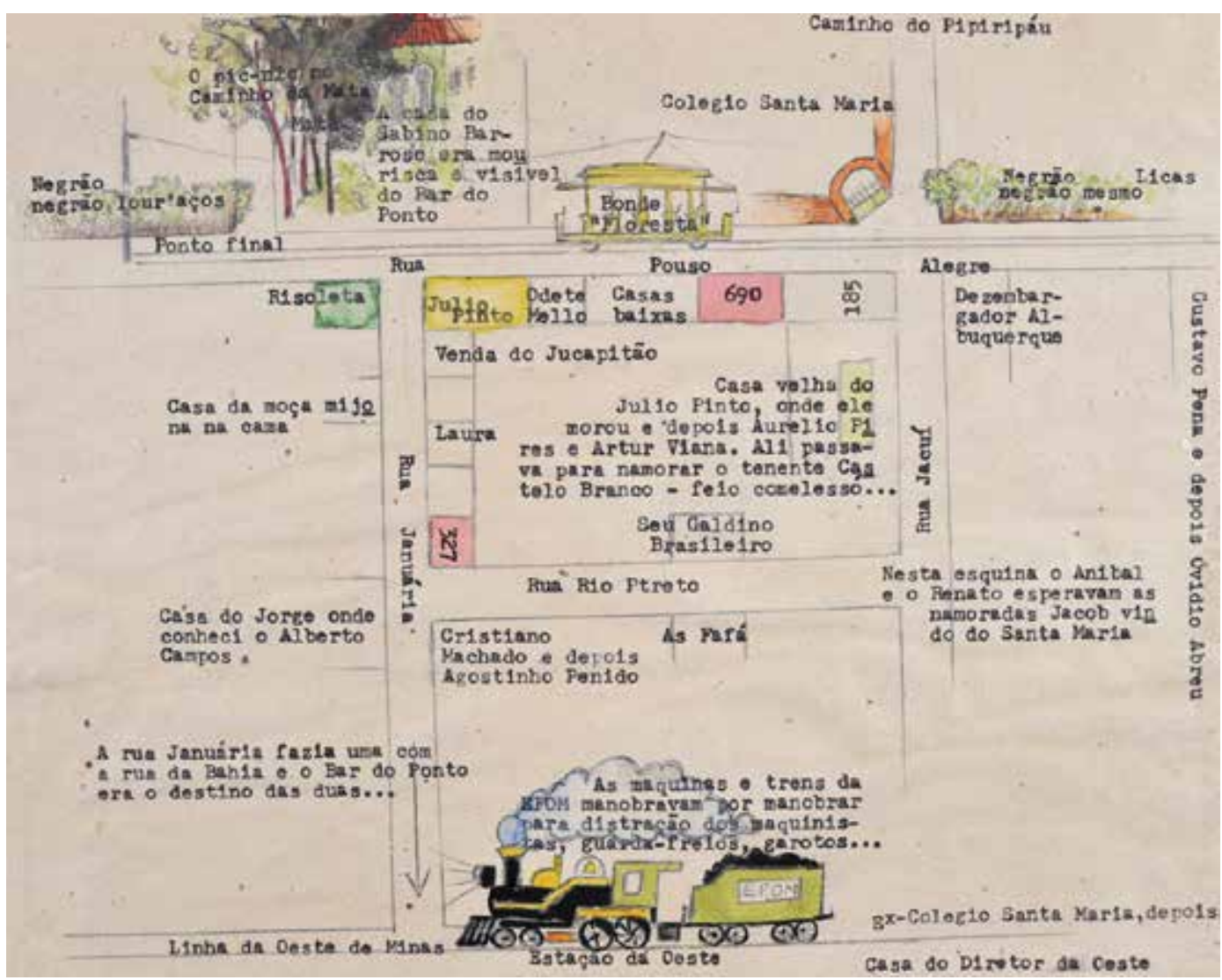

Pedro Nava, desenho, s.d. Mapa de Belo Horizonte.

Pasta Balão cativo.

Acervo Fundação Casa de Rui Barbosa/Arquivo

Museu de Literatura Brasileira 


\section{X M: MEMORIALISMO MODERNISTA MINEIRO}

As figurações do conflito entre indivíduo e sociedade no memorialismo de Pedro Nava são indícios empírico-textuais de uma surpreendente construção social cosmopolita da diferença cultural brasileira de que estamos nos ocupando, um grupo grande interdisciplinar de pesquisadoras e pesquisadores no projeto coletivo sobre o cosmopolitismo nas, a partir das, com as e contra as Minas Gerais. Como não se trata de fazer um mapa sobre o regionalismo mineiro, nosso esforço está antes na abertura potencial de nossos temas e também nas possibilidades comparativas decorrentes. Assim, estamos entendendo o cosmopolitismo mineiro como o tipo de relação descentrada de convivência com o universal a partir da diferença local, que implica movimento e abertura em várias direções. Por isso, minha questão no projeto diz respeito justamente a como, nesse conflito entre indivíduo e sociedade, se reconhece a existência própria de uma subjetividade individual que, como nos ensina um último Michel Foucault, existe como práticas de cuidados de si. Cuidados de si precários, desafiantes e frágeis sempre e ainda mais numa família e numa sociedade de matrizes patriarcais. Assim, é também de políticas de reconhecimento de subjetividades individuais, de suas promessas nem sempre realizadas e de seus limites e paradoxos sociais num mundo cosmopolita brasileiro que se trata. ${ }^{2}$

Adiante, quando os resultados da pesquisa comparada em curso sobre Pedro Nava e outros autores estiverem disponíveis, será possível voltar de outro modo às caracterizações da hermenêutica do sujeito no memorialismo mineiro, lidas a partir de sua codificação específica em cada texto e no uso que se faz dos dispositivos disponíveis para essas escritas de si. Escritas essas, não custa lembrar, que são o ato da própria elaboração da subjetividade a partir das construções de temas e formas como a infância, o espaço, o tempo, o corpo, o sonho etc., em seu papel complexo de expressão da demanda singular e relação com as sobredeterminações culturais e simbólicas a que estão submetidas as palavras.

Recebido em 7/5/2020 | Aprovado em I4/7/2020

André Botelho é professor-associado do Departamento de Sociologia e do Programa de Pós-Graduação em Sociologia e Antropologia da Universidade Federal do Rio de Janeiro. É ainda pesquisador (IC) do CNPq e Cientista do Nosso Estado da Faperj. Autor, entre outros, de O retorno da sociedade. Política e interpretações do Brasil. 


\section{NOTAS}

* O autor agradece a Joaquim Jaguaribe Nava Ribeiro a autorização para utilizar as imagens do arquivo Pedro Nava do Museu da Literatura Brasileira da Casa de Rui Barbosa neste artigo.

I O projeto é uma iniciativa interinstitucional coordenada por Eneida Maria de Souza (UFMG), Mariana Chaguri (Unicamp), Maurício Hoelz (UFRRJ), Pedro Meira Monteiro (Princeton Univeristy) e por mim. Agradeço aos colegas os comentários a esse texto. Agradeço ainda a Andre Bittencourt e aos editores e pareceristas de Sociologia \& Antropologia.

2 Nessa próxima etapa o trabalho será desenvolvido com Lucas Van Hombeeck.

\section{REFERÊNCIAS BIBLIOGRÁFICAS}

Araújo, Ricardo Benzaquen de. (2004). Através do espelho: subjetividade em Minha formação, de Joaquim Nabuco. Revista Brasileira de Ciências Sociais, 19/56.

Armstrong, Nancy. (2009). A moral burguesa e o paradoxo do individualismo. In: Moretti, Franco (org.). A cultura do romance. São Paulo: Cosac Naify, p. 335-74.

Arrigucci Jr., Davi. (200I). Móbile da memória. In: Enigma e comentário: ensaios sobre literatura e experiência. São Paulo: Companhia das Letras, p. 67-II2.

Arruda, Maria Arminda do Nascimento. (1989). Mitologia da mineiridade. São Paulo: Brasiliense.

Bastos, Elide Rugai. (2006). As criaturas de Prometeu: Gilberto Freyre e a formação da sociedade brasileira. São Paulo: Global.

Beck, Ulrich. (20II). Sociedade de risco. Rumo a uma outra modernidade. São Paulo: Editora 34.

Beck, Ulrich \& Beck-Gersheim, Elisabeth. (2002). Individualization: institutionalized individualism and its social and political consequences. London: Sabe.

Bittencourt, Andre Veiga. (2017). A incisão e a lira: medicina, literatura e modernismo em Pedro Nava. Tese de Doutorado. PPGSA/Universidade Federal do Rio de Janeiro. 
Bomeny, Helena. (1994). Guardiães da razão. Modernistas mineiros. Rio de Janeiro: Editora da UFRJ/Edições Tempo Brasileiro.

Botelho, André. (2019). As memórias de Pedro Nava e a modelagem do modernismo mineiro. In: Miceli, Sergio \& Myers, Jorge. Retratos latino-americanos: a recordação letrada de intelectuais e artistas do século XX. São Paulo: Edições Sesc, p. 257-268.

Botelho, André. (2012). As memórias de Pedro Nava: autorretrato e interpretação do Brasil. In: Nava, Pedro. Baú de ossos. São Paulo: Companhia das Letras.

Botelho, André \& Hoelz, Maurício. (2016). Sociologias da literatura: do reflexo à reflexividade. Tempo Social. Revista de Sociologia da USP, 8/3.

Brasil Jr., Antonio \& Botelho, André. (2017). Florestan Fernandes para dimensionar a força do presente. In: Botelho, André \& Starling, Heloísa. República e democracia: impasses do Brasil contemporâneo. Belo Horizonte: Editora UFMG, p. 205-22I.

Candido, Antonio. (2006a). Ficção e confissão. Ensaios sobre Graciliano Ramos. Rio de Janeiro: Ouro sobre Azul.

Candido, Antonio. (2006b). Poesia e ficção na autobiografia. In: A educação pela noite. 5 ed. Rio de Janeiro: Ouro sobre Azul, p. 6I-86.

Foucault, Michel. (2016). Subjetividade e verdade. São Paulo: Martins Fontes.

Foucault, Michel. (2006). A hermenêutica do sujeito. São Paulo: Martins Fontes.

Freyre, Gilberto. (I98I). Sobrados e mucambos. Rio de Janeiro: José Olympio.

Giddens, Anthony. (2002). Modernidade e identidade. Rio de Janeiro: Zahar.

Lahire, Bernard. (2004). Retratos sociológicos; disposições e variações individuais. Porto Alegre: Artes Médicas.

Lahire, Bernard. (2002). O homem plural: os determinantes da ação. Petrópolis: Vozes.

Lejeune, Philippe. (2000). O pacto autobiográfico. Belo Horizonte: Editora UFMG. 
Martuccelli, Danilo \& Singly, François de. (20I2). Las sociologías del individuo. Santiago: LOM Ediciones.

Miranda, Wander Mello. (2009). Corpos escritos. São Paulo: Edusp.

Santiago, Silviano. (2008). Cadê Zazá? Ou a vida como obra de arte. In. O cosmopolitismo do pobre. Belo Horizonte: Editora UFMG.

Santiago, Silviano. (1989). Prosa literária atual no Brasil. In: Nas malhas da letra. São Paulo: Companhia das Letras. Santiago, Silviano. (I98I). Em liberdade: uma ficção de Silviano Santiago. Rio de Janeiro: Paz e Terra.

Schwarz, Roberto. (1997). Outra Capitu. In. Duas meninas. São Paulo: Companhia das Letras.

Simmel, Georg. (20II). Georg Simmel on Individuality and Social Forms. Edited by Donald Levine. Chicago: University of Chicago Press.

Watt, Ian. (2010). A ascensão do romance: estudos sobre Defoe, Richardson e Fielding. São Paulo: Companhia das Letras. 
Palavras-chave Individualização; cosmopolitismo; indivíduo e sociedade; memorialismo.

Keywords

Individualization; cosmopolitanism; individual and society; memoirs.

\section{MINAS MUNDO: HERMENÊUTICA DE UMA} SUBJETIVIDADE INDIVIDUAL

\section{Resumo}

Busco nesse registro de pesquisa circunscrever de um ponto de vista sociológico o entrelaçamento entre subjetividade individual e cosmopolitismo na cultura brasileira no e a partir do memorialismo de Pedro Nava. Duas experiências de pesquisa o informam. No ponto de partida original, atividades múltiplas em torno de Nava nos últimos dez anos: como pesquisador, professor em sala de aula, orientador de tese e organizador da reedição da sua obra. Na outra extremidade, que, no entanto, não é apenas um ponto de chegada, mas também um novo ponto de partida, essas experiências são em parte reorientadas com vistas ao projeto coletivo "Minas mundo: o cosmopolitismo na cultura brasileira" que estamos iniciando numa grande rede de pesquisa e cooperação interdisciplinar, nacional e internacional.

\section{MINAS WORLD: THE HERMENEUTICS OF AN INDIVIDUAL SUBJECTIVITY}

Abstract

In this research record, I outline a sociological approach to the entanglement between individual subjectivity and cosmopolitanism in Brazilian culture, in and through the memoirs of Pedro Nava. Two research experiences inform the text. At the original point of departure, multiple activities concerning Nava over the last ten years - as researcher, classroom teacher, thesis supervisor, and editor of republications of his work. At the other end, which is not, though, merely a point of arrival but also a fresh point of departure, these experiences are partly reoriented towards a collective project, "Minas world: cosmopolitanism in Brazilian culture," which we are launching in a large national and international network of interdisciplinary research and cooperation. 